\title{
Factors Affecting the Adoption of Environmental Management Systems by Crop and Livestock Farms in Canada
}

\author{
Udith K. Jayasinghe-Mudalige and Alfons Weersink*
}

\begin{abstract}
This study examines, both qualitative and quantitatively, the motivation for crop, livestock, and mixed (both crop and livestock) farms in Canada to behave environmentally responsibly by adopting Environmental Management Systems (EMS) in the farm and the impact of a number of human capital, financial, farm structure, and social characteristics of the farmer and/or the farm on this behavior. It uses the data from 16,053 farms that responded to the Farm Environmental Management Survey conducted by Statistics Canada and Agriculture and Agri-Food Canada in 2001, which collects information on implementation of EMS in the areas manure, fertilizer, pesticide, water, wildlife, grazing, and nutrient management in the farm.The outcome of analysis show that mixed farms have the highest adoption rates, in general, across the eight EMSs considered in this study, while livestock-only farms have the lowest. The most common EMSs used by all farms are fertilizer and pesticide management plans with the whole farm environmental plan as the least likely to be adopted. The results based on a regression analysis suggest that "young" and "rich" farmers with a "large" land extent tend to adopt as many as possible EMS, but the gender of the farmer does not show a significant impact on this behaviour. The level of urbanization and government regulation also affects significantly the level of adoption of EMSs. The analysis, as a whole, points out that even in the absence of "mandatory" national level policies to regulate agricultural farms in Canada, farmers show a tendency to adopt as much as possible EMS "voluntarily", because of their own interests in the farming environment and/or motives originating from the market where they operated with.
\end{abstract}

\footnotetext{
* The authors are affiliated to Department of Agribusiness Management, Faculty of Agriculture and Plantation Management, Wayamba University, Makandura, Gonawila (NWP) and Department of Agricultural Economics and Business, University of Guelph, Guelph, Ontario, Canada, N1G 2W1 respectively.
} 


\section{Introduction}

An environmental management system (EMS) is an example of an environmental-friendly production practice that documents a firm's activities that affect environmental performance. Generally, an EMS does not evaluate the effects of those practices on environmental quality but only records the use of the practices. Firms adopt an EMS if the benefits exceed the costs of doing so. The benefits include higher revenues through increasing market share or through price premiums as the EMS provide a credible signal to its existing and potential customers that it is an "environmentally-friendly" firm. Cost savings may result directly from efforts to conserve the factors of production used in its day-to-day operations and/or reduce the waste generated in such activities. It could also indirectly accrue to the firm in the process of thoroughly evaluating its management practices. Costs could be further reduced by an EMS by means of lower interest rates charged by financial institutions; lower premiums charged by insurance companies, and lower liability risks (e.g. compensation, legal fees) by minimizing the risk of involvement of the judiciary to solve the cases related to the environmental quantity (Khanna and Anton, 2002). For example, an EMS can be used as evidence of due diligence which is often the only acceptable defense in a legal challenge stemming from an environmental accident (Wall, Weersink and Swanton, 2001).

Aside from affecting financial performance directly, the management of the firm may be motivated by a moral concern for environmental quality and can use an EMS as a guide to reducing its ecological impact. The use of an EMS, moreover, may allow the adopting firm to improve its public image / reputation with the community (Henriques and Sadorsky, 1996). The pressures to adopt may not only come internally but also externally from its customers (private), and the government (public) (Segerson and Miceli, 1998). Trade associations with which the firm has strong business relationships can request to have one or more EMS at the firm level (Khanna, 2001). In addition, a firm may adopt an EMS as a proactive response to limit the possibility of future environmental regulations being imposed on them by government.

The benefits and costs associated with the adoption of a single best management practice (BMP) have been examined empirically in the context of agricultural sectors in many developed countries. For example, the factors affecting adoption have been studied for integrated pest management techniques by D'Souza et al. (1993), for vaccines by cattle producers by Bhattacharyya et al. (1997), for use 
of fertilizers and pesticides by Smith and Smithers (1992), for soil conservation techniques by Rahm and Huffman (1984), and for irrigation by Casewell and Zilberman (1985). However, the impact of biophysical, human capital and economic variables on the adoption of environmental management systems in agriculture has not been examined despite their growing use by farmers with and without government prompting.

The purpose of this study is to estimate the factors affecting the adoption of environmental management systems by crop and livestock farms in Canada. It uses data collected in the Farm Environmental Management Survey (FEMS) conducted in 2001 by Statistics Canada and sponsored in part by Agriculture and Agri-Food Canada. The next section of the paper describes the data including the eight environmental management systems considered in the study. The following section summarizes the adoption rates for individual EMSs. The results of the regression analysis assessing the determinants of adoption are then presented, followed by a discussion of the conclusions and implications of the results.

\section{Methods}

The Farm Environmental Management Survey (FEMS) was a voluntary national survey focusing on the level of adoption of best management practices on livestock and crop operations in all provinces across Canada. The target population of the survey was all active farms with sales greater than $\$ 10,000$ as found in the Agriculture Division's Farm Register in Canada. The FEMS data was also tied to the 2001 Census of Agriculture.

The structured questionnaire used in this survey defined an EMS as a "formal, written plan prepared by a trained person or specialist to cover certain operational aspects of the farm", and it gathered information on the use of eight such EMS, namely; (1) whole farm environmental plan (WFEP); (2) manure management plan (MMP); (3) fertilizer management plan (FMP); (4) pesticide management plan (PMP); (5) water management plan (WMP); (6) wildlife conservation plan (WCP); (7) grazing management plan (GMP), and (8) nutrient management plan (NMP) (Table 1). The questionnaire was administered nationally with a sample of 21,000 crop and livestock farms. There were 16,053 questionnaires returned. The high response rate $(76.4 \%)$ may be due to the backing of two prominent government institutions, which have close connections with the country's farming sector - Statistics Canada, and Agriculture and Agri-Food Canada. Farms that responded to the questionnaire were categorized into 
Table 1: Definition of environmental management practices

Type

of

Definition

EMS

WFEP An overall assessment of environmental issues or concerns related to the farm

MMP Explains the types of liquid, solid/semi-solid manure storage systems used (e.g. unlined lagoon, open tank, Sealed, covered tank etc.), frequency of storage and use of manure; specific treatments used (e.g. aeration, additives, separation, drying etc.), and odor control systems etc.

FMP Explains the measures used to apply fertilizer (e.g. broadcasting, banded, post-plant top/side dressing etc.); mix of legume and chemical fertilizer to be used in each season, and their frequencies etc.

PMP Explains certain information with respect to different application strategies of herbicide, insecticide, and fungicide; sprayer calibration techniques, and alternative methods other than chemical pesticides to control weeds, insects ad diseases etc.

WMP Explains the sources and total volume of water to be used on a per acre basis; methods used to irrigate the land (e.g. sprinkler, drip, surface flooding etc), and ways and means of domestic water testing etc.

WCP Explains any measures taken to conserve natural land and wildlife habitants that are adjacent to the agricultural operation (e.g. livestock fencing, cultivation of perennial forage, trees, bushes etc).

GMP Explains any measures taken to conserve natural wetlands including rotational grazing for livestock and practices such as "carry-over" and "re-seeding".

NMP Explains the methods of testing nutrient content of the farm's liquid or solid/semi-solid manure before applying it to the land; consideration of nutrient carry-overs; distance to water ways, and timing of applications etc. 
three major categories: (1) "crop farms" ( $\mathrm{n}=5,425)$, (2) "livestock and (3) "mixed farms" $(\mathrm{n}=8,378)$.

\section{Empirical Model of Adoption Decision}

The aim of this analysis is to examine the impact of various factors affecting the adoption of EMS in a crop and/or livestock farm. It was hypothesized that a farmer with higher concerns about the farming environment will adopt a higher number of EMS and this behaviour is, however, motivated by a number of factors pertaining to the farmer and the farm, including the human capital (age, sex), financial (profits, non-farm income), farm structure (size, ownership), and social characteristics. (distance, population pressure). Farmers adopting more EMS than less have the ability to minimize many of the potential problems related to the management an EMS on their farming operation, and subsequently increase profits.

The following empirical model has in turn been specified to test the factors affecting adoption of EMS: (1)

$$
\mathrm{EMS}_{i}^{\mathrm{m}}=\beta_{0}+\Sigma \beta_{i j} \mathrm{X}_{i j}+\varepsilon_{i}
$$

where, $\mathrm{EMS}^{\mathrm{m}}{ }_{\mathrm{i}}$ is the dependent variable of the model representing the number of EMSs $(\mathrm{m}=1,2 \ldots 8)$ adopted by farm $i(\mathrm{i}=1,2, \ldots n), \mathrm{X}_{i j}$ is a vector of $\mathrm{j}$ explanatory variables representing human capital, financial, and social characteristics, $\beta_{i j}$ is the regression coefficient corresponding to the explanatory variables $(\mathrm{j}=1,2, \ldots l)$ and $\varepsilon_{i}$ is the random error term assumed to have a mean of 0 . There are three categories of explanatory variables developed for the purpose of analysis: human capital, financial and social characteristics. The definitions of the variables and their expected signs $(+$ or - within brackets) are given below.

Human capital characteristics include: (1) $A G E$ - age of the farm household head in years (+); (2) SEX - gender of the farm household head with male $=1$ and female $=0$; and (3) $T M \_A L L$ - time allocation of the farm household head with full-time farmer $=1$ and part-time farmer with off-farm work $=0$.

Financial characteristics pertaining to the farmer and his operation include: (1) SAL_OPEX overall profitability of the farm calculated by taking the ratio of total gross farm receipts of the operation in 2000 to total farm business operating expenses in 2000 of the farm (+); (2) NF_INC - measures the non-farm income earned by the head of the farm household through certain activities outside the farm, for example retail business and factory work etc., with non-farm income $=1$ and no non-farm income $=0$, and (3) FIX_AST - total present market value of land, buildings, and farm 
machinery measured in thousands of Canadian dollars $(+)$.

Farm characteristics capture the operational and structural characteristics of the farm. Four business arrangements are possible and three dummy variables were constructed to capture the range of possibilities. A partnership, however, without any formal agreement with any partner was assumed to be the base scenario. The other three dummy variables include (1) $O R G \_S P$ - sole proprietorship $=1$ and other arrangements (i.e. for partnerships / corporation) $=0$; (2) $O R G_{-} F C$ - family corporation $=1$ and 0 otherwise and (3) $O R G \_N F C-$ non-family cooperation $=1$ and 0 otherwise. In addition, several variables were included to examine the land ownership patterns: (4) $O W N \_T L A$ - ratio of own land to the total land area of the farm (+), (5) $L G O \_T L A$ - ratio of land leased from the government to the "total land area of the farm (-), (6) FM_SIZE the land area of the farm in hectares $(+)$.

Finally, social and regional characteristics were taken into account: (1) DIST - demarcates the distance in kilometers "as a crow flies" from the farm operation to the nearest Census Metropolitan Area (CMA) (-). It is assumed that more remote the farm, the less likely it will be to adopt an EMS due to lower resource mobility. (2) POP_DEN the population density of the Census
Sub-Division where the farming operation is located measured as the number of people per square $\mathrm{km}(+)$. We assume that the number of EMSs adopted by a farm increases with population density since there will be greater social pressure for the farm to be environmentally friendly. Finally, a series of dummy variables to indicate the Province where the farm is located were included to assess the impact of Provincial government regulations on the EMS adoption decision. Dummy variables were constructed for Quebec, Ontario, Manitoba, Saskatchewan, Alberta, and British Columbia with the Atlantic Provinces as the base dummy.

\section{Results and Discussion}

\section{EMS Adoption Rates}

The adoption rates of the 8 EMS among the three types of farms are reported in Table 2. Mixed farms have the highest adoption rates in general across the eight EMSs considered while livestock-only farms have the lowest. The most common EMSs used by all farmers are the fertilizer management plan and the pesticide management plan. A whole farm environmental plan is the most comprehensive of the possible EMSs options, but it is the least likely to be adopted. The number of EMS adopted by an individual farm was estimated for all 
three types of farms (Table 3). The results show that approximately 55 percent of farms in the sample (i.e. $8764 / 16053 * 100)$ did not adopt even a single EMS. Another 11.7 and 8.6 percent of farms in the sample adopted a single and two EMSs, respectively. Mixed farms have a tendency to adopt more EMS on the farm at the same time than crop and livestock farms. For example, about 10.8 percent of mixed farms adopt more than four EMSs on the farm while only 4.0 percent and 1.5 percent of crop and livestock farms, respectively, adopt that many EMSs.

Table 2: Rates of adoption of different EMS by crop, livestock, and mixed farms

\begin{tabular}{ccccccccc}
\hline \multirow{2}{*}{$\begin{array}{c}\text { Type of } \\
\text { Plan }\end{array}$} & \multicolumn{2}{c}{ Livestock } & \multicolumn{2}{c}{ Crop } & \multicolumn{2}{c}{ Mixed } & \multicolumn{2}{c}{ Total } \\
\cline { 2 - 9 } & \multicolumn{2}{c}{$\mathrm{N}=2,250$} & \multicolumn{2}{c}{$\mathrm{N}=5,425$} & \multicolumn{2}{c}{$\mathrm{N}=8,378$} & \multicolumn{2}{c}{$\mathrm{N}=16,053$} \\
\hline & $\mathrm{No}$ & $\%$ & $\mathrm{No}$ & $\%$ & $\mathrm{No}$ & $\%$ & $\mathrm{No}$ & $\%$ \\
\hline WFEP & 150 & 6.7 & 564 & 10.4 & 1304 & 15.6 & 2018 & 12.6 \\
MMP & 309 & 13.7 & 255 & 4.7 & 2187 & 26.1 & 2751 & 17.1 \\
NMP & 7 & 0.3 & 804 & 14.8 & 1263 & 15.1 & 2074 & 12.9 \\
FMP & 66 & 2.9 & 1493 & 27.5 & 2163 & 25.8 & 3722 & 23.2 \\
PMP & 55 & 2.4 & 1478 & 27.2 & 1762 & 21.0 & 3295 & 20.5 \\
WMP & 261 & 11.6 & 988 & 18.2 & 1838 & 21.9 & 3087 & 19.2 \\
WCP & 215 & 9.6 & 653 & 12.0 & 1365 & 16.3 & 2233 & 13.9 \\
GMP & 320 & 14.2 & 155 & 2.9 & 2081 & 24.8 & 2556 & 15.9 \\
\hline
\end{tabular}

Table 3: Number of EMS adopted by individual farms

\begin{tabular}{crrrrrr}
\hline \multirow{2}{*}{$\begin{array}{c}\text { No of } \\
\text { EMPs }\end{array}$} & \multicolumn{2}{c}{ Livestock } & \multicolumn{2}{c}{ Crop } & \multicolumn{2}{c}{ Mixed } \\
\cline { 2 - 7 } Adopted & $\begin{array}{c}\text { No of } \\
\text { Farms }\end{array}$ & \multicolumn{1}{c}{$\%$} & $\begin{array}{c}\text { No of } \\
\text { Farms }\end{array}$ & $\%$ & $\begin{array}{r}\text { No of } \\
\text { Farms }\end{array}$ & $\%$ \\
\hline 0 & 1396 & 62.0 & 3026 & 55.8 & 4342 & 51.8 \\
1 & 277 & 12.3 & 677 & 12.5 & 925 & 11.0 \\
2 & 203 & 9.0 & 572 & 10.5 & 608 & 7.3 \\
3 & 137 & 6.1 & 496 & 9.1 & 594 & 7.1 \\
4 & 104 & 4.6 & 354 & 6.5 & 623 & 7.4 \\
5 & 71 & 3.2 & 175 & 3.2 & 539 & 6.4 \\
6 & 35 & 1.6 & 92 & 1.7 & 458 & 5.5 \\
7 & 19 & 0.8 & 26 & 0.5 & 207 & 2.5 \\
8 & 8 & 0.4 & 7 & 0.1 & 82 & 1.0 \\
Total & 2250 & 100.0 & 5425 & 100.0 & 8378 & 100.0 \\
\hline
\end{tabular}


Correlation Coefficients between Different EMS

Before presenting the regression results explaining the number of EMS adopted by a farm, correlations between the uses of the eight different EMS across farms were examined. The idea was to verify whether there is any overlap with respect to farmers' understanding and interpretation of the specified tasks in each system. The correlation coefficients reported in Table 4 are low for the majority of elements in the matrix. For example, the correlation coefficient exceeds 0.5 only in 7 elements of the matrix. The highest value obtained was 0.741 between pesticide management plan (PMP) and the fertilizer management plan
(FMP), which indicates that the same farmers are likely to adopt both PMP and FMP. This suggests that farmers perceive, in general, each system has its own role to play (i.e. One plan cannot be substituted with another completely). Consequently, adoption of multiple EMSs may be required to achieve the environmental and/or business objectives of the farm.

\section{Regression Results}

Ordinary least squares (OLS) techniques were used to estimate equation (1) and the resulting parameter estimates are reported in Table 5 for each of the three farm types. The overall fit was good for cross-sectional data as the adjusted R-square values were approximately 0.7 .

Table 4: Correlation coefficients between the EMS for mixed farms:

\begin{tabular}{ccccccccc}
\hline & NMP & WFEP & MMP & FMP & PMP & WMP & WCP & GMP \\
\hline NMP & 1.000 & & & & & & & \\
WFEP & 0.418 & 1.000 & & & & & & \\
MMP & 0.319 & 0.264 & 1.000 & & & & & \\
FMP & 0.319 & 0.270 & 0.643 & 1.000 & & & & \\
PMP & 0.274 & 0.265 & 0.410 & 0.741 & 1.000 & & & \\
WMP & 0.202 & 0.198 & 0.537 & 0.547 & 0.487 & 1.000 & & \\
WCP & 0.153 & 0.149 & 0.427 & 0.430 & 0.377 & 0.556 & 1.000 & \\
GMP & 0.117 & 0.121 & 0.517 & 0.441 & 0.365 & 0.526 & 0.492 & 1.000
\end{tabular}


There were three variables, namely $A G E, \quad S A L \_O P E X$ and $F M \_S I Z E$, which were significant at 1 percent level in all three models, and possess the expected signs.

Thus, the number of EMSs adopted by a farm increases with the age of the farmer, farm profitability and farm size. Similarly, farms that owned most of their land were also more likely to adopt more EMSs suggesting that the long-term benefits of an EMS are more likely to accrue to an operation with a longterm commitment to their land as opposed to short-term interests if the land is leased. Many other variables, for example NF_INC, FIX_AST, $O R G \_S P, \quad O R G \_F C, \quad O W N \_T L A$, $D I S T$ and POP_DEN were significant at various levels in all three samples. All these also possessed the expected sign. As expected, farmers tend to adopt more EMS the closer the farm is to a major urban center (DIST). Similarly, adoption increases with the Population density of the region in which the farm is located. Thus, farms operating in the urban milieu are subject to greater pressures from the community to behave in more environmentally friendly manner, and thus are more likely to adopt more EMSs. The time allocated by livestock farmers on their operation has a significant relationship with the adoption of EMS, although that for other two farm types did not show such a relationship. Likewise, sustainability measured in terms of use of capital assets (FIX_AST) has only significantly associated with livestock farmers.

The dummy variables included to measure the impact of government regulation were significant in all models for Ontario and Alberta suggesting that the present regulations or the potential of future regulations in these provinces are encouraging EMS adoption. In terms of the size of the estimate, those farms located in Quebec $\left(P_{-} Q C\right)$ have tendency to adopt more EMS than those from other Provinces. For example, in the livestock model, the size of the estimate of $P_{-} Q C$ is 0.5191 while it is much low in other provinces. The results highlight the importance of regional regulations on the likelihood of EMS adoption.

\section{Conclusions and Policy Implications}

The outcome of the analysis suggests that a number of factors affect significantly on farms' decisions to adopt various types of environmental management systems. It was revealed that younger the farmer that he/she tends to adopt as many as possible EMS in the farm in order to minimize the potential hazards that could be occurred if the environment in and around the farm is not controlled and/or to receive the end products specified in each plan, in terms of increased benefits and decreased costs to the farm. However, the gender of the farmer 
does not show a significant impact on this behaviour showing that both men and women farmers tend to behave with equal responsibility and the accountability of his/her farm. The financial status of the farm as well as its size, in fact, has a positive relationship with this behaviour. As expected, "rich" farmers with a "large" land extent tend to adopt more practices. Another important finding is that the impact of urbanization and government regulation on these farms to behave responsibly environmentally. Those farms located in populated areas in certain Provinces in Canada with strict government regulations, for example Quebec and Ontario, used to adopt more EMS than less, in general.

The results provide some useful insight into the formulation of agricultural policy, in general, and environmental policy, in particular. It points out that even in the absence of mandatory "national level" policies to regulate agricultural farms in Canada, in the areas discussed in this paper such as manure management, pesticide management, farmers show a tendency to adopt as much as possible environmental management practices voluntarily, because of their own interests in the farming environment and/or motives originating from the market where they operated with, for example reputation and reduced insurance premiums. Interestingly, this behaviour did not varied to a great extent with respect to the farming type (i.e. livestock, crop or mixed), as the results indicate that majority of those variables are significant in all these models.

The outcome of the analysis, unfortunately, cannot be taken, as a whole, to discuss the validity and relevance, and in turn to formulate appropriate agricultural and environmental policies for crop and livestock farming sectors in Sri Lanka since, to the best knowledge of the authors, there has been no comparable empirical analysis conducted on this issue to date in the country. However, with increasing concerns amongst agriculturists and environmentalists as well as policy makers towards having some sort of control with respect to the misuse of natural resources, for example by applying of chemical pesticides and fertilizers on agricultural lands indiscriminately, and many other problems associated with deforestation and taking away of wildlife habitats for cropping and raring of livestock etc. highlight the necessity of adopting farmer and environmentally friendly agricultural policies in the areas discussed above.

The authors wish to express their gratitude to $\mathrm{Mr}$. Mike Trant and Mr. Martin Beaulieu, Agriculture Division of the Statistics Canada and Prof. Brady Deaton, Dept. of Agricultural Economics \& Business, University of Guelph. 


\section{References}

Bhattacharyya, A., T. R. Harris, W. G. Kvasnicka, and M. Veserat. (1997). Factors Influencing Rates of Adoption of Trichomoniasis Vaccine by Nevada Range Cattle Producers. Journal of Agricultural and Resource Economics. 22(1):174-190.

Casewell, M. and D. Zilberman. (1985). The Choices of Irrigation Technologies in California. American Journal of Agricultural Economics. 67:224-234.

D'Souza, G., D. Cyphers, and T. Phipps. (1993). Factors Affecting the Adoption of Sustainable Agricultural Practices. Agricultural and Resource Economics Review (October). 159-165.

Henriques, I. and P. Sadorsky. (1996). The Determination of an Environmentally Responsive Firm: An Empirical Approach. Journal of Environmental Economics and Management .30(3):381-395.

Khanna, M. and W. R. Anton. (2002)

Corporate Environmental Management: Rgulatory and Market-based Pressures. Land Economics 78 (4): 539-558.
Khanna, M. (2001). Non-Mandatory Approaches to Environmental Protection. Journal of Economic Surveys. 15(3):291-324.

Rahm, M. R. and W. E. Huffman. (1984). The Adoption of Reduced Tillage: The Role of Human Capital and Other Variables. American Journal of Agricultural Economics. 66:405-413.

Segerson, K. and T. J. Miceli. (1998). Voluntary Environmental Agreements: Good or Bad News for Environmental Protection? Journal of Environmental Economics and Management. 36(2):109-130.

Smithers, J. and M. Furman. (2003). Environmental Farm Planning in Ontario: Exploring Prticipation and the Endurance of Change. Land Use Policy. 20(3):343356.

Smith, B. and J. Smithers. (1992). Adoption of Soil Conservation Practices: An Empirical Analysis in Ontario, Canada. Land Degradation and Rehabilitation. 3:1-14. 
Wall, E., A. Weersink and C. Swanton. (2001).

Agriculture and ISO 14000.

Food Policy. 26(1):35-48. 